
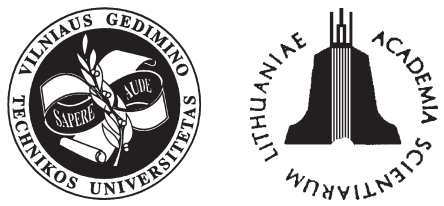

ISSN 1648-4142 TRANSPORT

http:/www.vtu.lt/english/editions

TRANSPORT - 2005, Vol XX, No 3, 111-116

\title{
ANALYSIS OF TRANSPORT PERFORMANCE INDICATORS
}

\author{
Margarita Išoraitė \\ Law University of Lithuania, Ateities g. 20, LT-08303 Vilnius-57, Lithuania, E-mail: misorait@ltu.lt
}

Received 2004-11-12; accepted 2005-03-25

\begin{abstract}
The article analyses the following issues: 1) key performance indicators, 2) best value indicators, 3) performance indicators and the change process, 4) transport programme indicators inputs, outputs, results and impacts, 5) indicators of effectiveness, efficiency and performance, 6) overcoming of the problems of using indicators, 7) criteria of the establishment of performance indicator system.
\end{abstract}

Keywords: transport performance, transport performance indicators.

\section{Introduction}

The saying "What gets measured gets done" illustrates the importance of the right things being measured and inappropriate things being left out. If transport organisation does not measure what it values, it will end up valuing what can be measured. The choice of indicators will have a major impact on the operation and direction of the organisation, knowledge of the factors driving behaviour and influencing performance thus become crucial. The development of robust and meaningful transport performance indicators is a major challenge [1-4]. Transport performance indictors may be set by external agencies (e.g. the government), or by personnel at any level within an organisation. They may be set privately and informally by an individual used to measure his or her work rate or productivity. Among the important features which could also be relevant for developing sustainable transport indicators in Europe are:

* A large number of indicators have been set up in the transport and environment area. They cover 'physical' environmental outcomes as well as the behaviour of actors in the transport sector and specific responsibilities of government.

* Indicators are designed for use in major management decisions such as budget allocations.

* Large institutional frameworks have been created to manage, improve and independently control the quality of the performance indicators.

\section{Key performance indicators}

Key performance indicators (KPIs) are indicators used to report the progress towards delivery on factors identified as critical to the success of transport organisation's goals and objectives. In progressive environment KPIs can also serve as tools for change providing input into process management that will assist in bringing about sustainable performance improvements. Ideally, the identification of KPIs should help to identify the root causes of problems or deficiencies. There are five elements that are essential to any KPI-based management system:

1. A statement of the appropriate objectives.

2. KPIs that are measurable and tied into the overall strategic plan.

3. Programmes to achieve the objectives.

4. Solid costing programmes and the accounting means and methods for getting good cost information.

As most government managers already know, defining KPIs is very difficult. It can also be highly contentious as soon as you start crossing functional and organisational boundaries. So it is all too easy to fall into the trap of defining KPIs in functional or sectional terms and to find the relevant data in local databases to measure signs of local progress. This often creates a "comfort zone" enabling individual managers to point to local quality improvements without reference to broader policy objectives. Such localised optimisation can actually be counter-productive from a customer's perspective and can lead to conflicts of interest between functions and departments. For example, one function's efforts to "streamline" a process and to increase throughput may simply create more work further down the chain, perhaps for customer-facing functions. While everyone in the organisation has a role to play in performance improvement, to get the full value from a KPIs manage- 
ment system KPIs should be defined from a top-down, strategic perspective by managers with the power to promote change. Moreover a top-down approach to information is required to achieve an integrated "customer-centric" view of performance. The information that must be brought together typically resides in several different places scattered across departmental and functional boundaries. Consider, as a very highlevel example, the government policy initiatives to reduce "social exclusion". The same individuals are likely to appear on several different databases and information in any one of these only gives a partial view of an individual's predicament.

\section{Best value indicators}

The best value performance indicators can be used in assessing and reporting according to five dimensions of performance:

1. Strategic objectives - why the service exists and what it seeks to achieve.

2. Costs/efficiency - the resources committed to a service: the efficiency with which they are turned into outputs.

3. Service delivery outcomes - how well the service is being operated in order to achieve the strategic objectives.

4. Quality - -explicitly reflecting user's experience of services.

5. Fair access - relating to case and equality of access to service.

Any effective performance indicator communicates information about the level of activity/performance in an organisation.

Performance indicators are integral to the meaningful assessment of activity, whether by an individual or an organisation. They provide a comparator and tool for measuring performance levels for analysis:

* Within an organisations at discrete points in time, and over a period time;

* In comparison with other organisations, both public and private.

Indicators may be used on a basis of increasing productivity/activity levels through the setting of target activity levels - performance targets.

By quantifying the levels of performance targets can be set and performance measured to ensure a minimum standard is attained.

Through careful and thorough planning and by monitoring performance indicators transport organisations can ascertain the extent to which policies and strategies are being met.

By measuring activity levels and communicating performance indicators as targets they may be used as a management tool by line managers to motivate individuals or groups of staff.

In setting performance targets for others managers motivate individuals or groups of staff.

In setting performance targets for others managers may find it more simple and effective to consult the relevant individual. This will have the following benefits:

* the individuals concerned are more likely to feel motivated to achieve a performance level of which they have had part - ownership.

* staff is likely to have greater specialised knowledge of realistic performance targets.

* the setting of difficult but achievable performance targets may motivate staff to consider the way in which they perform the task allotted to them and to investigate whether this might be performed in a more efficient manner.

Conversely, where management sets performance targets for teams or an individual member of staff without consultation individuals may feel alginate and undervalued and are less likely to be motivated by the performance targets set.

In setting organisation - wide performance indicators it should be note that where operations can be geographically spread a performance target and satisfactory performance level may be realistic in one location. They may be an unrealistic target in another.

This might be the case where operating conditions, market, local demographics and many other socio - economic conditions differ between regions. Where operations are widely geographically separate and operating conditions are very different, the comparison of crude performance indictors between one location and another will be meaningless.

To be of value as a tool to consist in implementing such changes, performance targets and indicators should be smart [5]:

* Specific. The subject of the target should be simple and clear.

* Measurable. The target should be quantifiable and easily measurable. Targets that require lengthy computation of data from many different sources are unlikely to be cost - effective and resource costs of calculating the chosen variable may outweigh any benefit derived of it.

* Achievable. The target set should be achievable. If unrealistically high targets are set, motivation is lost. Conversely, where realistic targets are set, personnel has been observed to experience in increase not just in "productivity", but also in reward. Staff may experience a greater sense of job satisfaction in reaching targets, especially where they have been consulted in setting them.

* Relevant. The targets measured should be pertinent to the operation in question. 
* Timely. All targets should be set within a specific time frame.

Performance indicators may be set for individuals, teams of individuals or for the organisation as a whole.

Organisation - wide performance indicators are known as corporate performance indicators.

At a corporate level authorities need to develop a range of performance indicators as a basis for monitoring their performance across all services and activities. These should reflect the progress towards the attainment of strategic and corporate objective, priorities and underpinning values.

Performance indictors may be used for different organisational purposes:

* Cultural change - e.g. from administrative to managerial.

* Realignment of focus - e.g. inward - looking to customer oriented.

* Education of personnel - in concepts such as accountability and service;

* initiating, monitoring and evaluating change - e.g. following the adoption of strategic plan, or the introduction of re-engineering;

* providing opportunity for a "reality check", to ensure that progress towards immediate and ultimate objectives is being made.

The dangers of establishing and implementing range performance indicators as a management tool include the following:

- The effective use of performance indicators relies upon their relevance to the function being measured/managed. Once set, indicators should be regularly reviewed to ensure that any operational changes have not rendered the performance indictors obsolete or misleading.

- Strict adherence to achieving the performance targets set from the agreed performance indicators should not become and end in it.

* Some aspects of service provision may be difficult to express as a performance indicator. The most obvious example of this is quality. It could be argued that since it is the quality that has the most direct impact on outcomes, its capacity to express and measure quality in terms of performance indictors renders the use of performance indicators less than ideal.

\section{Performance indicators and the change process}

The function of performance indicators is a key at all the stages of the change process:

* In the early stages of change they are vital in assessing the organisation's present position.

* From the analysis of relevant data performance objectives and any necessary changes can be planned by identifying critical success factors (those requirements that an organisation needs to satisfy most in order to achieve the desired outcome).

* During the implementation of the change performance indicators are needed to monitor the success of the progress of change in the critical success factors.

* Finally, reference to performance indicators provides the measure by which the results of the change process are evaluated.

This evaluation process should be considered in the terms of (see Fig):

* Economy - to obtain appropriate resource input at minimum cost;

* Efficiency - to generate maximum output from input;

* Effectiveness - to ensure outputs achieve desired results;

* Equity - to ensure rewards of achievement are fairly shared.

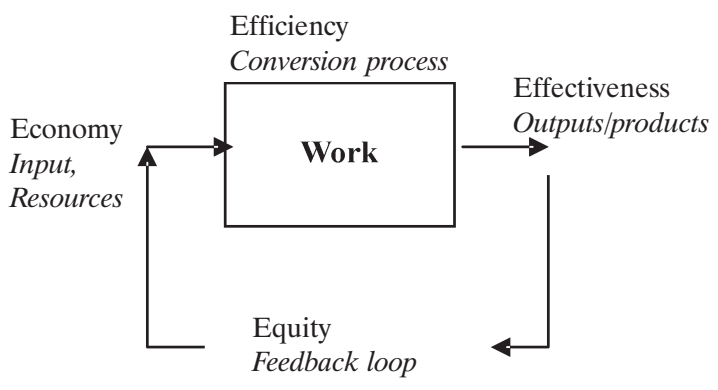

The evaluation process

\section{Transport programme indicators: inputs, outputs, results and impacts}

To be able to monitor transport programme implementation and to judge its performance against the objectives set it is necessary to use a set of indicators which must be decided in advance or early in the transport programme implementation, so that the data on them can be collected. They in most cases will be assigned target levels which in aggregate will correspond to the objectives of the programme. The various levels of indicators are as follows (see Table 1):

* Resource or input indicators refer to the budget allocated to each level of the assistance. Financial indicators are used to monitor the progress in the terms of the (annual) commitment and payment of the funds available for any transport operation, measure or programme in relation to its eligible costs.

* Output indicators relate to transport activity. They are measured in physical or monetary units (e. g. length of road constructed, number of transport organisations financially supported, etc.). 
* Result indicators relate to the direct and immediate effect brought about by a programme. They provide information on changes of, for example, the behaviour, capacity or performance of direct beneficiaries. Such indicators can be of physical (reduction in journey time, number of successful trainees, number of road accidents, etc.) or financial (leverage of private sector resources, decrease in transportation cost) nature.

* Impact indicators refer to the consequences of the programme beyond the immediate effects on its direct beneficiaries. Specific impacts are those effects occurring after a certain lapse of time but which are, nonetheless, directly linked to the action taken. Global impacts are long term effects affecting a wider population. Clearly, measuring this type of impacts is complex and clear causal relationships are often difficult to establish.

Table 1. Possible indicators for a major infrastructure project (road construction)

\begin{tabular}{|c|c|c|}
\hline & Description & Indicators \\
\hline Output & $\begin{array}{l}\text { Construction } \\
\text { of road }\end{array}$ & $\begin{array}{l}\text { Implementation: } \\
\text { - financial: cost, state of } \\
\text { progress } \\
\text { - physical: km constructed, } \\
\text { level of progress }\end{array}$ \\
\hline Results & $\begin{array}{l}\text { Reduced } \\
\text { journey time } \\
\text { and } \\
\text { transport } \\
\text { costs }\end{array}$ & $\begin{array}{l}\text { - Accessibility } \\
\text { - Time savings (in min) } \\
\text { - Cost savings (\%) }\end{array}$ \\
\hline $\begin{array}{l}\text { Specific } \\
\text { impact }\end{array}$ & $\begin{array}{l}\text { Increased } \\
\text { safety } \\
\text { Increased } \\
\text { flows of } \\
\text { persons and } \\
\text { goods } \\
\end{array}$ & - Traffic flows \\
\hline $\begin{array}{l}\text { Global } \\
\text { impact }\end{array}$ & $\begin{array}{l}\text { Increased } \\
\text { socio- } \\
\text { economy } \\
\text { activity }\end{array}$ & $\begin{array}{l}\text {-diversification of production } \\
\text { - net job creation } \\
\text { - increased regional GDP per } \\
\text { capita and per occupied person }\end{array}$ \\
\hline
\end{tabular}

\section{Indicators of effectiveness, efficiency and perfor- mance}

Evolution must address a set of specific issues and enable the assistance to be addressed in detail. Using the indicators we can measure such concepts as effectiveness and efficiency (see Table 2).

* Efficiency compares what has been done with what was originally planned, i.e., it compares actual with expected or estimated outputs, results, and/or impacts.

Effectiveness and efficiency ratios can then be calculated for each stage of the programme or measure, i.e., in terms of output, result and impact. They allow the comparison of what has been achieved with what was planned (effectiveness) or with the resources used (efficiency). These indicators can provide useful information for programme managers and evaluation, assisting them to make better (re) programming decisions.

Table 2. Effectiveness and efficiency indicators [6]

\begin{tabular}{|l|l|l|l|}
\hline & Indicators & Effectiveness & Efficiency \\
\hline $\begin{array}{l}\text { Operational } \\
\text { objective } \\
\text { (measure/ } \\
\text { operation) }\end{array}$ & $\begin{array}{l}\text { Financial/ } \\
\text { physical } \\
\text { output }\end{array}$ & $\begin{array}{l}\text { Actual/planned } \\
\text { output }\end{array}$ & $\begin{array}{l}\text { Output } \\
\text { compared with } \\
\text { cost }\end{array}$ \\
\hline $\begin{array}{l}\text { Specific } \\
\text { objective }\end{array}$ & Result & $\begin{array}{l}\text { Actual/planned } \\
\text { output }\end{array}$ & $\begin{array}{l}\text { Result } \\
\text { compared with } \\
\text { cost }\end{array}$ \\
\hline $\begin{array}{l}\text { Global } \\
\text { objective }\end{array}$ & Impact & $\begin{array}{l}\text { Actual/planned } \\
\text { output }\end{array}$ & $\begin{array}{l}\text { Impact } \\
\text { compared with } \\
\text { cost }\end{array}$ \\
\hline
\end{tabular}

Examining efficiency entails the following questions. Can the same results be produced using less input? Alternatively, can the same amount of input produce more results? Related to such question is the problem of comparing the programme or resource with its possible alternative. The main difficulty here is the choice of appropriate benchmarks. Benchmarks should preferably be established in advance so as to permit appropriate comparisons and clarify the quantification of objectives during the programming phase.

It is also important to consider that even if a programme is efficient it might still contain serious shortcomings in its design Objectives might not, for example, have been expressed with sufficient clarity or could even be absent entirely. In this respect evaluators can perform a valuable role transforming vague or global objectives into quantified, verifiable targets.

It is also worth considering that the concept of effectiveness tends to concern just one aspect of the programme effects, i.e., the expected positive results. Programme can also produce unexpected positive and negative results which the agreed indicators might not be able to detect.

\section{Overcoming the problems of using indicators}

The indicators produced by the monitoring systems should provide information useful to improve the quality and effectiveness of assistance. They should also be relevant and measurable at different stages of programme implementation.

Indicators are not always easy to use. Some of the problems which can arrive are:

* There can be difficulties in establishing clear cause - and effect relationships between the planned 
actions, results achieved and impacts with regard to the final objectives.

* The relative complexity of measurement methods can also be problematic. Outputs and results are relatively straightforward to measure that they are quite close to the "measure" level. In contrast, impacts must be measured from the outside of operational context. They need not be particularly visible or obvious and this has adverse consequences in terms of their measurability. In addition, an impact is often the cumulative effect of a number of measures and it can further complicate the analysis.

* Data can be unavailable at crucial decision making stages.

* There are difficulties in combining certain indicators. Whereas financial indicators can be aggregated to all levels (measure, priority, programme), physical indicators are more difficult to aggregate, and it may be sometimes inappropriate to do so. It is important to choose the appropriate physical indicators for each level of assistance in order to be able to measure the corresponding quantifiable results and impact. Monitoring indicators tend to be more readily established and quantified when they relate to the measure or project level. They are difficult to define and to use at a more aggregated level (programme, priority). It is therefore essential not simply to define indicators, but to use quantitative (and qualitative) information about various items assistance.

* It is important to capture, as far as possible, the indirect or unexpected effect of assistance (e.g. substitution effects) which influences the results and impacts particularly those relating to job creation and maintenance.

\section{Criteria of the establishment of a performance in- dicator system}

There are some important principles and questions to be asked at the very beginning [7]:

- What system of transport indicators is to be used?

- Will indicators contribute to the identification of the best practice or good practice?

- Will indicators of the best or good practice be accepted and be used by all the participants at all levels (staff, authority, all government levels)?

- Will participants use the indicators and key performance indicators as an internal management tool?

- How will areas for a change process or continuous improvement programme be prioritised?
When vital principles have been established and recorded as an organisation written agreement between the parties involved, some further work is needed to establish the basis of the key performance indicator system. The development system depends on:

- The identification and understanding of the operation or sectors of operation.

- The use of indicators which, as a set, outline relevant dimensions of the undertaking but without being so large that they cannot be used in a concise and practical fashion.

- The development of a logical hierarchy of indicators which can be split for use at differing levels.

- The establishment of definitions and data sources which remain consistent between all parties to the exercise throughout so that even when data or indicators are changed the source and definition of the old or new retain within the database.

- A pragmatic view of which indicators and key performance indicators have the most influence and potential improvement of the undertaking whilst the benchmarking exercise proceeds.

- Acceptance by all participants that initially not everyone will be able to provide all requested data.

Any key performance indicators must be capable of being influenced by the participants at any level in the exercise but particularly by the management, authority. The primary and secondary key performance indicators must include information about reliability service quality, efficiency, safety, assets/capacity utilization, financing, regulatory and environmental policies.

Apart from these operations based datasets to complete the pictures should be possible to seek to collect a standardised set of customer focused data and national, regional or city indictors. The customer focused data to be obtained from surveys enables the levels of customer or "end user" satisfaction to be reviewed. The national, regional or city indicators enable a view to be taken on demographics, land use and political policies and practice - all of which impact on the undertaking and the way it performs. The chosen indicators are supported by a high quality dataset which must be:

- collected in a uniform way;

- controlled in an independent and analytical manner;

- analysed so that inconsistencies can be referred back to source for review;

- subject to an agreed confidentiality protocol where necessary.

In this process it is not sufficient to collect data and analyse it once. Continuing analysis and the collection of supporting data will enable the progressive 
improvement of the understanding of background, environmental, and political factors. The collection of data on a continuing basis with increasing attention paid to the secondary indicators has benefits not only in the volume of data available, but also in the maturing of the data quality. This has another benefit in allowing all participants to have the perception of the process and a better knowledge of their own undertaking.

\section{Conclusions}

1. Transport performance indicators are not the end of a process, but should be used as a starting point to illustrate differences within or between undertakings to identify areas for further examination or analysis.

2. Defined transport performance indicators that are useful identifiable and do not measure more than resources allow or the task at hand requires.

3. Prior to choosing transport performance indicators identify clear objectives, agree on a strategy for using results, and brief and seek acceptance from those involved.

4. If transport performance indicators do not tell the whole story, set up special groups to study the issues do not create more data.

5. It is important to learn from the experience within and outside Europe in order to maximise the value of the range of data and indicators initiatives that are being undertaken both by the European Commission and other international organisations.

\section{References}

1. Kennerly, M.; Neely, A. A framework of the factors affecting the evolution of performance measurement systems. International Journal of Operations \& Production Management, Vol 22, No 11, 2002, p. 1222-1245.

2. Audit Commission. Management paper on target the practice of performance indicators. London, 2000, p. 8-15.

3. Audit Commission. Management paper aiming to improve the principles of performance measurement, London, 2000, p. 11-12.

4. Keel, J.; Hawkins, A.; Lawrence, F. Alwin. Guide to performance measure management, 1999, Texas.

5. European Commission. Ex ante evaluation. A practical guide for preparing proposals for expenditure programmes, December 2001, p. 13-15.

6. CIMA. Setting effective performance indicators in a best value environment, 2000, p. 10-18.

7. Draft recommendations to BOB pilot participants and DG TREN, Resulting from best Conference 3, Indicators and Benchmarking in the Transport Sector, June 2001, p. 8. 